\title{
Weiter- und Fortbildung für heute und morgen
}

Der Geschäftsbericht 2019 gibt uns wiederum die Gelegenheit, mit Zahlen und Fakten einen Überblick über die Tätigkeit und die Projekte des Schweizerischen Instituts für ärztliche Weiter- und Fortbildung SIWF zu geben. Zudem gehen wir auf aktuelle Herausforderungen der ärztlichen Weiter- und Fortbildung ein, wobei ein Schwergewicht auf der Fortbildung und ihrem Weg zur beruflichen Weiterentwicklung liegt.

Die Zahlen dokumentieren den grossen und zunehmenden Arbeitsanfall, der von den Mitarbeitenden des Instituts zu bewältigen ist. Ihnen danken wir deshalb an dieser Stelle für ihr Engagement besonders herzlich. Sie setzen sich dafür ein, Gesuche um Titelerteilung und Anträge auf Anerkennung als Weiterbildungsstätte korrekt und speditiv zu bearbeiten. Das Gleiche gilt für die Ausschreibung der Awards und der Projektförderung, die Durchführung von Workshops und die Organisation der rund hundertfünfzig Visitationen, die für die Qualitätssicherung unentbehrlich sind. Dazu kommen die unzähligen Auskünfte auf Anfragen zu den Erfordernissen der Weiterbildung aus dem Inund Ausland.

Der Kernauftrag des SIWF beschränkt sich aber keineswegs auf administrative Arbeiten. Die schnellen Veränderungen im Gesundheitswesen, der Strukturwandel an den Spitälern und die Knappheit zeitlicher und finanzieller Ressourcen verlangen von Geschäftsleitung und Vorstand laufend Überlegungen und Massnahmen für die Aktualisierung des ärztlichen Bildungssystems. Dazu gehören neben der Revision der Weiterbildungsprogramme mit besonderem Blick auf die Lernzielkataloge auch zwei IT-Grossprojekte: das neue e-Logbuch für alle Weiterzubildenden und der Ausbau der Fortbildungsplattform für alle aktiven Ärztinnen und Ärzte.

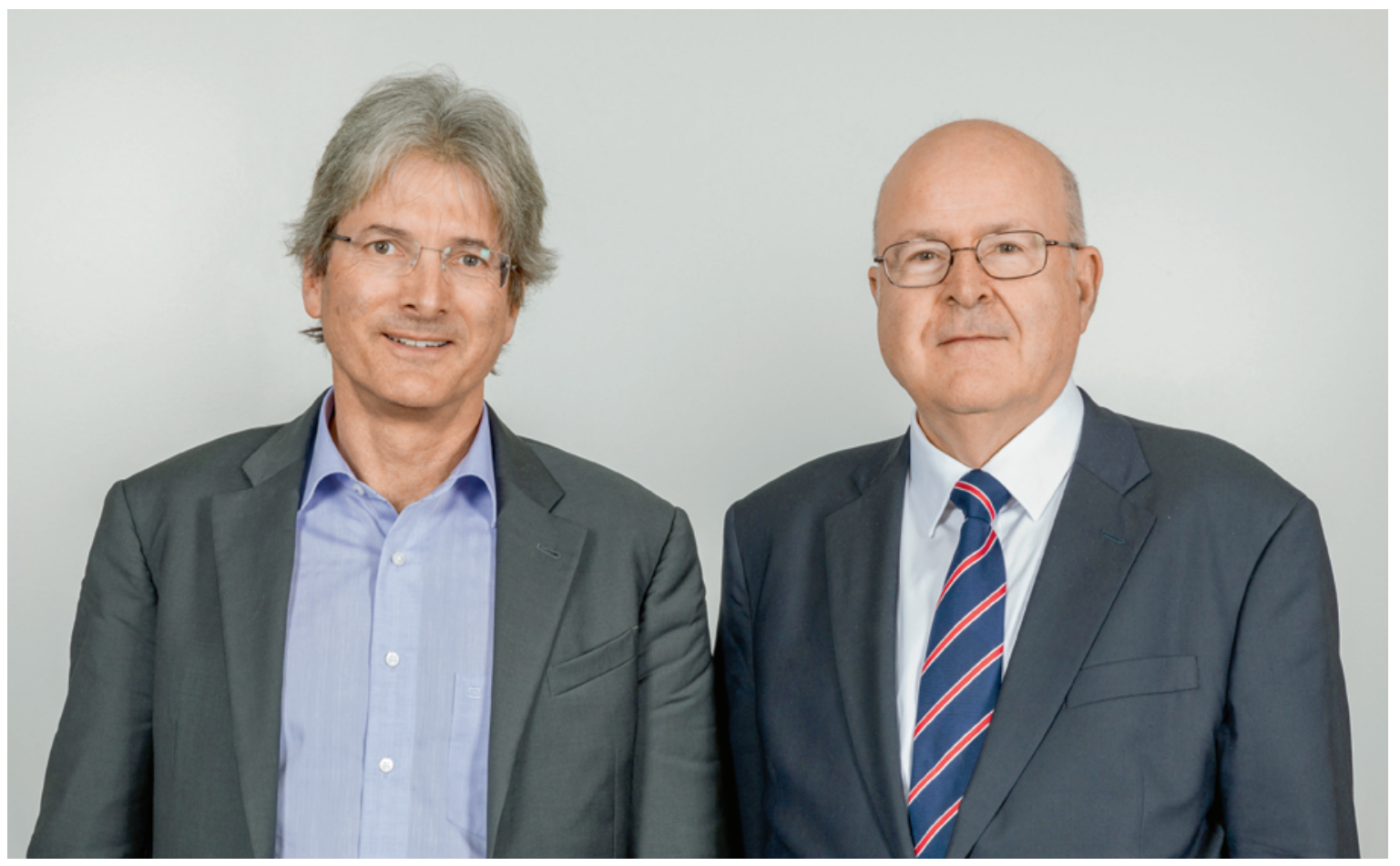

Christoph Hänggeli, Rechtsanwalt, Geschäftsführer SIWF, und Dr. med. Werner Bauer, Präsident SIWF. 